\title{
Molina Campano, Eduardo Manuel. La filosofía política de Toni Negri. Un debate abierto sobre la renovación de la teoría marxista. Sevilla. Atrapasueños, 2018.
}

\author{
Fernando Martínez Cabezudo \\ Área de Filosofía del Derecho \\ Universidad Pablo de Olavide
}

Fecha de recepción: 13/05/2019 I De publicación: 27/06/2019

En este libro el autor nos presenta un profundo análisis de la filosofía política del célebre pensador Antonio Negri. El punto de partida de Eduardo Molina consiste en establecer un diálogo con las proposiciones principales del italiano para debatir con los autores centrales del marxismo y aportar una posición propia en una conversación virtual desarrollada sobre los ejes temáticos más importantes del filósofo.

Molina se muestra como un profundo conocedor de las escuelas marxistas presentando no solo un punto de vista particular, sino que es capaz de contemplar las diferentes perspectivas, tanto de los representantes de las interpretaciones ortodoxas como los de las más heterodoxas. Negri es un prolífico pensador de la máxima relevancia en los desarrollos modernos del materialismo político. Su posición está dotada de una gran complejidad teórica y se sumerge en debates clásicos donde el entrecruzamiento de aportaciones exige del investigador un profundo conocimiento del campo. Este factor queda solucionado con solvencia, el autor expone con claridad y síntesis las principales variables en discusión de manera que la narración consigue introducir con facilidad temas de enorme complejidad.

El trabajo está dividido en tres grandes capítulos temáticos coronados con conclusiones parciales cada uno de ellos. Finalmente se expone una conclusión general donde se integran los principales puntos destacados a lo largo de la investigación. Antes de pasar propiamente con el comentario de cada uno de los capítulos es importante destacar el estilo claro y conciso del autor, tanto las exposiciones de los pensamientos Negri como las críticas y puntualizaciones a estos están expuestos 
de manera didáctica y con intención de aportar perspectivas nuevas al debate, tanto en el plano epistémico como histórico.

En el primer capítulo Eduardo Molina centra sus reflexiones en una de las cuestiones fundamentales que recorren toda la historia de las diferentes corrientes de análisis marxistas desde prácticamente su inauguración. Nos estamos refiriendo al comentario sobre los escritos de la estrategia leninista de transición hacia el comunismo, la discusión de las diferentes fases del socialismo y la mejor construcción del mismo. En un primer término se ofrecen unos planteamientos básicos sobre los postulados acerca de la cuestión que servirán como ejes sobre los que irá girando un debate tripartito entre Lenin, Negri y el propio autor. A lo largo de este se establecen puntos críticos, aclaraciones históricas e interpretaciones alternativas, entre las que destacan las puntualizaciones a las fases teóricas de la revolución y su interpretación. Tomando conceptos de Negri sobre la fase histórica del socialismo, las relaciones que tiene con su precedente capitalista y la posibilidad de un cambio "suave" o "abrupto", pero usándolos de una manera diferente, propone una visión alternativa que integra perspectivas ortodoxas con las matizaciones y conceptos heterodoxos extraídos de la interpretación del transalpino.

En el segundo de los Capítulos cambiamos las proposiciones filosófico-políticas para centrarnos en unos de los nudos gordianos de la Economía Política de corte materialista: las cuestiones sobre la Ley del Valor-Trabajo. Para esta problemática viajamos de la mano del autor por los comentarios de Negri a los Grundrisse eligiendo como texto central el ya célebre Marx más allá Marx y apoyándose en El Trabajo Inmaterial para la última parte saliendo. Sin embargo, el autor va un poco más allá del mero comentario del comentario y analiza con precisión diferentes cuestiones que el autor italiano trata de una forma más tangencial en sus trabajos. Problemáticas que son un rubicón esencial en las diferentes corrientes marxistas, como el estudio de las Leyes Tendenciales del Capital, en la heterodoxa postura de Negri no quedan visibilizadas en primer plano, sin embargo, el autor las introduce con la ayuda de un amplio conocimiento bibliográfico sobre la materia.

El último de los capítulos está dedicado a uno de los trabajos más insignes y respetados de Negri. En este tercer acto nos centraremos en Imperio como categoría analítica relativa a la nueva configuración del sistema capitalista que enunciara el transalpino. A diferencia de los dos capítulos anteriores en esta última entrega no nos centramos tanto en discusiones cerradas de las teorías de 
análisis histórico-materialistas, sino en establecer una relación con autores no marxistas y las implicaciones y coincidencias entre estos y Negri para entender la proposición de Imperio e imperialismo. En este último punto la concepción de las Relaciones Internacionales se torna básica y el autor demuestra el suficiente dominio para poder exponer sin problemas temas complejos como el encaje de las teorías de la dependencia con las del sistema-mundo wallresteiniano, así como, las implicaciones de las asunciones basadas en dialécticas hegelianas que podrían ser interpretadas dentro de las proposiciones del propio Negri.

Para finalizar tenemos una conclusión concisa y sincera donde el autor deja intuir un plan de trabajo para llevar más allá las investigaciones en este libro tratadas. Con Negri como guía, nos lleva por cuestiones relativas a los puntos más importantes del profesor italiano, aportando una mirada crítica y cargada de reflexión sobre los elementos más importantes y espinosos que conlleva la producción de un autor tan prolífico y con tanto impacto Antonio Negri. 